I.J. Povo-Martín ${ }^{\mathrm{a}, *}$, D. Gallego-Vilar ${ }^{\mathrm{a}}$, M. Rodrigo-Aliaga ${ }^{\mathrm{a}}$ y J. García-Vilab

aservicio de Urología, Hospital General de Castellón, Castellón, España
bServicio de Radiología, Hospital General de Castellón, Castellón, España

*Autor para correspondencia.

Correo electrónico: Ivanjp82@hotmail.com (I.J. Povo-Martín).

\title{
Melanoma de uretra masculina: caso clínico
}

\section{Melanoma of male urethra: A clinical case}

\section{Sr. Director:}

Presentamos el caso de un varón de 71 años que manifestaba uretrorragia de diez días de evolución y aparición de una lesión pigmentada a través del meato urinario, sin otra clínica asociada. La exploración física, incluyendo la palpación de cadenas linfáticas inguinales, así como el hemograma y la bioquímica sanguínea, incluyendo marcadores tumorales, eran rigurosamente normales. La cistoscopia reveló la presencia de una lesión nodular, friable y grisácea, de unos $17 \times 7 \mathrm{~mm}$, en la fosa navicularis, que fue biopsiada. La anatomía patológica demostró una proliferación de células poligonales, con núcleos esféricos e hipercromáticos, que se teñían positivamente para HMB45, melanina A, vimentina y S100, siendo negativa para queratina. Todo ello fue compatible con el diagnóstico de melanoma primario de la uretra. Una TAC toracoabdominopélvica descartó afectación metastásica ganglionar o visceral. En ese punto, se realizó amputación parcial del pene, cuyos márgenes quirúrgicos fueron negativos. Se realizó técnica del ganglio centinela inguinal bilateral, resultando negativo, por lo que no se realizó linfadenectomía. Los resultados de la biopsia de uretra fueron confirmados en la pieza quirúrgica.

Durante el seguimiento de este paciente, se realizó una PET/ TAC a los seis meses y al año de la cirugía, que fueron normales. Seis meses después, el paciente presentó dolor y distensión abdominal de dos semanas de evolución, con signos de ascitis en la exploración, lo que llevó a la realización de una TAC toracoabdominal, que confirmó la presencia de líquido ascítico, así como engrosamiento del peritoneo, mesenterio, un conglomerado adenopático retroperitoneal, metástasis hepáticas bilobares de hasta $6 \mathrm{~cm}$, nódulos pulmonares múltiples y derrame pleural bilateral (fig. 1). En la analítica de sangre destacaba una LDH de $833 \mathrm{UI} /$. Se realizó una paracentesis, con obtención de líquido serohemático. Con el diagnóstico de recurrencia metastásica de melanoma, se inició tratamiento con quimioterapia paliativa con dacarbazina intravenosa, a dosis de $250 \mathrm{mg} / \mathrm{m}^{2}$ durante cinco días. Tres semanas después, el paciente presentó ascitis hemorrágica y fallo multiorgánico, añadiéndose pancitopenia secundaria al tratamiento con quimioterapia paliativa con dacarbazina intravenosa, lo que ocasionó la muerte del paciente pocos días después, a pesar del tratamiento farmacológico y de soporte.
Con respecto al melanoma de uretra, cabe destacar que es una variante muy infrecuente de melanoma, más aun en el varón, que conlleva un pronóstico infausto dada la naturaleza agresiva de la enfermedad y por su diagnóstico generalmente en estadios avanzados. Dada la dificultad de acceso de estas lesiones, los procesos de prevención secundaria de este tumor no son rentables. Aproximadamente un tercio de los pacientes tiene afectación linfática al diagnóstico, con una supervivencia global a los cinco años inferior al $30 \%{ }^{1,2}$. La clasificación de Breslow en estos melanomas es insuficiente, dada la mayor agresividad de esta enfermedad respecto a los melanomas cutáneos, por lo que en la práctica clínica se clasifican en: estadio i-II para la enfermedad localizada; estadio III si hay afectación linfática regional (inguinal), y estadio iv para la enfermedad metastásica ${ }^{2}$. Con respecto al tratamiento, sólo los estadios I-III son potencialmente curables, mediante cirugía lo más agresiva posible (penectomía total o parcial, con linfadenectomía si hay afectación ganglionar), con márgenes quirúrgicos microscópicos de al menos $2 \mathrm{~cm}$ libres de enfermedad, puesto que la uretrectomía parcial está asociada con un riesgo de recurrencia local del $50-70 \%$ en el primer año ${ }^{3}$. Sin embargo, este objetivo es difícil de alcanzar en los melanomas de uretra masculina, dado lo traumático de la amputación. Las técnicas de exenteración se reservan para pacientes con objetivo paliativo ${ }^{4}$.

La inmunoterapia adyuvante está indicada en casos con enfermedad residual tras la cirugía o en aquellos en los que

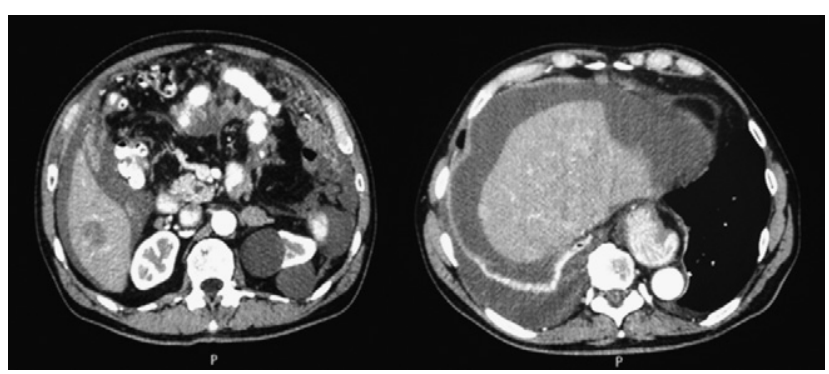

Figura 1 - Imágenes de la tomografía axial computarizada abdominal, en la que se objetivan metástasis hepáticas, líquido ascítico y nódulos retroperitoneales. 
hay afectación linfática (características que no presentaba el paciente descrito), siendo el tratamiento estándar el interferón- $\alpha 2 b$ a dosis de 20 millones de $\mathrm{UI} / \mathrm{m}^{2}$ cinco días por semana, durante 4 semanas, seguido de tratamiento de mantenimiento con dosis de 10 millones de $\mathrm{UI} / \mathrm{m}^{2}$ durante tres días por semana, durante 48 semanas. En pacientes con estadio Iv debe valorarse la quimioterapia con intención paliativa, siendo la dacarbazina o la temozolamida la primera línea, pudiéndose valorar el sorafenib+paclitaxel y carboplatino como segunda línea, aunque con muy pobres respuestas y supervivencia en la mayoría de los $\operatorname{casos}^{5-7}$.

B I B L I O G R A F Í A

1. Chang AE, Karnell LH, Menck HR. The national cancer data base report on cutaneous and noncutaneous melanoma: A summary of 84,836 cases from the past decade. Cancer. 1998;83:1664-78.

2. Patrick RJ, Fenske NA, Messina JL. Primary mucosal melanoma. J Am Acad Dermatol. 2007;56:823-34.

3. Sánchez-Ortiz R, Huang SF, Tamboli P, Prieto VG, Hester G, Pettaway CA. Melanoma of the penis, scrotum and male urethra: A 40-year single institution experience. J Urology. 2005;173:1958-65.
4. Nguyen AT, Kavolius JP, Russo P, Grimaldi G, Katz J, Brady MS. Primary genitourinary melanoma. Urology. 2001;57:633-8.

5. Agarwala SS, Keilholz U, Hogg D, Robert P, Hersey A, Eggermont $\mathrm{S}$, et al. Randomized phase III study of paclitaxel plus carboplatin with or without sorafenib in patient with advance melanoma. ASCO Annual Meeting Proceedings (Post-Meeting Edition). J Clin Oncol. 2007;25:8510.

6. Eigentler TK, Caroli UM, Radny P, Garbe C. Palliative therapy of disseminated malignant melanoma: A systemic review of 41 randomized clinical trials. Lancet Oncol. 2003;4:748-59.

7. Tawbi HA, Kirkwood JM. Management of metastatic melanoma. Semin Oncol. 2007;34:532-45.

L. Cabezón Gutiérrez ${ }^{a}$, I. Márquez-Rodas ${ }^{\mathrm{a}, *}$, A. Soria Lovelle ${ }^{\mathrm{a}}$, A. Martín Marino ${ }^{b}$, R. Álvarez Álvarez ${ }^{a}$ y A.J. Muñoz Martín ${ }^{a}$

aservicio de Oncología Médica, Hospital General Universitario Gregorio Marañón, Universidad Complutense, Madrid, España

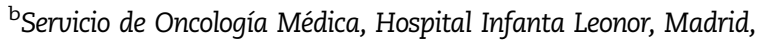
España

*Autor para correspondencia. Correo electrónico: ivanpantic@hotmail.com (I. Márquez-Rodas). 